\title{
Online Cognitive-Behavioral Group Therapy to Enhance Self-Esteem in Romantic Relationship for Emerging Adult Women
}

\author{
Diajeng Tri Padya ${ }^{1,}$ Lathifah Hanum ${ }^{2 *}$ \\ 1,2 Faculty of Psychology, Universitas Indonesia, Depok, Indonesia \\ *Corresponding author. Email: lathifah.hanum08@ui.ac.id
}

\begin{abstract}
Emerging adulthood is often linked with the development task to explore an intimate relationship with people around them, including establishing romantic relationships. However, individuals sometimes are hesitant to start a romantic relationship because of various reasons, and one of them is low self-esteem. Therefore, this study aims to develop an online group therapy with a cognitive-behavioral approach for emerging adult women with low self-esteem. Participants of this research are 14 women ranging from 20-25 years old who have difficulties in starting a romantic relationship caused by low self-esteem. This study used Rosenberg's Self-esteem Scale to measure the level of self-esteem in the participants. The results showed a significant difference between mean scores before and after the online group therapy ( $p=0.009$; Cohen's $d=1.43)$, which means that online group therapy with CBT approach can improve the emerging adult women's self-esteem who have difficulties starting a romantic relationship.
\end{abstract}

Keywords: cognitive-behavioral therapy, emerging adult women, online group therapy, romantic relationship, self-esteem.

\section{INTRODUCTION}

The journey of an individual's life from adolescence to adulthood is frequently associated with many changes. The emerging adulthood period is an individual growth and development at 18-25 years old [1]. In this period, individuals are no longer in the adolescence stage but have not yet reached adulthood. They often encounter challenges to explore in various aspects, including in romantic relationships with partners.

Those in the emerging adulthood stage have a great need to explore three aspects of their lives, namely love, work/career, and knowledge [1]. Regarding exploration in various domains of life, Luciano, and Orth [2] stated that in the range of late adolescence to early adulthood, individuals face various critical developmental transitions, and one of them is building romantic relationships. According to DeGenova [3], a romantic relationship or dating is an activity that involves a meeting between two people who carry out activities together, intending to get to know each other. Due to previous research, romantic relationships are a vital life domain that can affect individuals' well-being [4]

According to Orth et al. [5], self-esteem stands as a factor that can affect individuals' success in carrying out various life roles, including building romantic relationships. It is defined as a global selfevaluation to determine whether a person feels good or bad [6]. Furthermore, Baron, Branscombe, and Byrne [7] argued that self-esteem is an attitude that an individual has towards himself/herself, whether he/she views himself/herself positively or negatively. An individual's attitude towards himself/herself is critical because it will be related to how he/she behaves.

In general, self-esteem is classified into two categories, namely high and low. Individuals with a high or tend to have a positive level of self-esteem will be able to feel that they are quite useful and valuable, and can respect themselves as they are, but are not in a position of admiring themselves excessively or demand others to admire them [8]. On 
the other hand, individuals with low levels of selfesteem or negative self-esteem might become too sensitive, unstable, insecure, and tend to protect themselves from things that seem to hurt them potentially. Therefore, those with low self-esteem tend to be afraid to take risks and opportunities to actualize themselves, and they also find it difficult to enjoy their lives [8].

A high level of self-esteem is needed to undergo a period of emerging adulthood because, at this time, individuals have a great need to explore various aspects of their lives, so that they need to master new skills to support the exploration process and create a sense of worth for themselves. In exploring the aspects of romantic relationships, low self-esteem often makes individuals hesitate or reluctant to start relationships. This phenomenon is explainable by various characteristics.

Based on online survey results in a preliminary study of individuals aged 18-25 years, around 400 participants (most of which were women) claimed to have difficulty starting romantic relationships. The results revealed that women aged 18-25 years have a desire to build romantic relationships with other people but find it challenging to start a relationship because they feel insecure (including feelings of being less beautiful, less attractive, and not having an ideal body shape), feeling unworthy of love, finding difficulty to disclose, and trauma from the past relationship. Such feelings show that problems related to romantic relationships in women aged 1825 years can be influenced by self-esteem. The survey results also indicated that individuals' selfesteem is related to how they assess their body or appearance. There are indications that participants who filled out the survey were reluctant to initiate romantic relationships because of their low selfesteem and negative body image.

The data revealed above showed that individuals' self-esteem is often related to how they perceive their physical appearance or body image. This statement is in line with of Harter's opinion, who stated that the most accurate predictor of individual perceptions of their physical appearance is self-esteem [9]. Furthermore, Clay, Vignoles, and Dittmar [10] found that negative body image is associated with lower self-esteem levels. Individuals with low self-esteem show self-rejection, self-dissatisfaction, selfcontempt, and lack of self-respect, and often have unpleasant self-related images [11]. The level of self- esteem and body image are also vital indicators of achieving success in facing various challenges owned by individuals [12].

The development of self-esteem in individuals is a continuing process from childhood to adulthood. Therefore, self-esteem is open to changes in certain situations, even in adulthood [8]. Based on this thought, the individuals' level of self-esteem is very likely to be improved. Because the level of selfesteem will help individuals to adapt to developmental tasks more effectively, it is necessary to carry out intervention programs that can help individuals, which are, in this case, women aged 1825 years, to deal with various conditions related to romantic relationships effectively. As previously described, the vital link between self-esteem and body image makes interventions designed to increase self-esteem can also reduce dissatisfaction with the body/appearance [13]. Interventions for individuals with low self-esteem are also necessary because selfesteem is an essential factor in individual mental health [14].

Cognitive Behavioral Therapy (CBT) is considered useful in increasing self-esteem [15]. This intervention involves identifying dysfunctional beliefs that an individual has and turning them into more realistic, and it also involves behavior modification techniques. Since feelings and behavior are the thinking results (cognition), cognitive interventions can change an individual's thoughts, feelings, and behavior [16].

The implementation of CBT in this study would use a module conceptualized by Fennel [17] and adding psychoeducation material related to body image and romantic relationships. These adjustments were made based on the conditions faced by women aged 18-25 years who also showed a tendency towards a negative body image. Esplen and Tratchtenberg [18] stated that interventions with the CBT approach could be done individually, in pairs, or groups. Group intervention for women aged 18-25 years in this study was conducted online to minimize face-to-face meetings during the COVID-19 pandemic.

Interventions with the CBT approach that are carried out online have developed overseas as an alternative therapy. Several studies have supported the positive results of this online intervention. As the research results by Warmerdam, Straten, Jongsma, Twisk, and Cuijpers [19], online CBT can reduce 
dysfunctional attitudes, excessive worry, and negative orientation towards problems and increase feelings of empowerment for participants. Online CBT is also an intervention that can show positive results for participants with a negative body image [18].

Online CBT has advantages, some of which are cost-effective, reach more people, and are more efficient in their use of time [20][21]. However, online interventions also have some drawbacks. According to Andersson and Cuijpers [20], online CBT has shown effective results in mild psychological disorders, whereas individuals with severe clinical disorders such as depression tend not to show effective results. Furthermore, criticism of online CBT relates to the accuracy of providing a diagnosis to individuals, whereas online CBT generally relies on self-reports, which cannot replace diagnosis by professionals [20]. Besides, online CBT studies generally have small sample sizes and high dropout rates, so the intervention's effectiveness is questionable [20].

In Indonesia, research on online CBT in groups is relatively new, so there is no data on its effectiveness. Even though the various criticisms of online CBT, Ellis, Campbell, Sethi, and O'Dea [21] suggest that young individuals with mental health problems can still benefit from online interventions, it is enormous and can reach people who may not have received psychological treatment before. Based on this, online group intervention using the CBT approach to increase self-esteem in women aged 18-25 living in Indonesia is still worth trying so that they would be better prepared in establishing romantic relationships.

\section{METHOD}

\subsection{The group}

This study used a quasi-experimental method with a pretest-posttest nonequivalent control group design. The researchers recruited prospective participants online by opening registration via Google form. The participants' criteria were women aged 18 to 25 years, having difficulty initiating romantic relationships, heterosexual, and were willing to attend all the online sessions. Prospective participants having undergone the screening process are then interviewed by the researchers to ensure their homogeneity, such as having problems in starting romantic relationships because of the low level of self-esteem. The characteristics of individuals with low self-esteem referred to those proposed by Rosenberg and Owens [8]. The researchers also referred to individual characteristics that show a negative body image, such as self-rejection, selfdissatisfaction, self-disdain, lack of self-respect, and often having an unpleasant self-image [11].

From the interview results, prospective participants who showed a low level of self-esteem, a negative body image, and had the facility to carry out online intervention were selected as participants in this group intervention. Furthermore, the researchers provided a schedule of intervention activities to match each participant's schedule. Participants who matched the schedule then entered the experimental group, while the others entered the control group.

\subsection{Procedure}

The experimental group intervention consists of 7 sessions, divided into one pre-test and introduction session, five therapy sessions, and one post-test session. The duration of each session was between 60-150 minutes. The time interval between each session was approximately one week. Interventions were carried out online through the Zoom application so that participants and facilitators were at their respective homes/locations. The intervention facilitator was an adult clinical psychologist candidate who had received Cognitive-Behavioral Therapy training. The group intervention referred to the module proposed by Fennel [17] aimed at individuals with low self-esteem modified based on the participants' condition, who showed a negative body image tendency.

In the control group, participants were asked to fill out an online questionnaire twice with an interval of one month. After completing the questionnaire, participants in the control group received one online psychoeducation session (webinar), which covered most of the experimental group's material. The control group also obtained a summary of readings related to self-esteem, body image, and romantic relationships. 
Table 1. Overview of Curriculum

\begin{tabular}{|l|l|}
\hline Session & \multicolumn{1}{c|}{ Activity } \\
\hline Pre-session & $\begin{array}{l}\text { Introduction to the facilitator team and other participants; knowing an overview of online group } \\
\text { interventions; understanding the rules applicable; filling out the informed consent form; and } \\
\text { taking the initial measurement (pre-test). }\end{array}$ \\
\hline Session 1 & $\begin{array}{l}\text { Sharing experiences of difficulties in establishing romantic relationships with other participants, } \\
\text { recognizing common problems, and understanding the relationship between self-esteem and body } \\
\text { image and romantic relationships. }\end{array}$ \\
\hline Session 2 & $\begin{array}{l}\text { Recognizing thoughts and feelings related to a situation; understanding the link between thoughts } \\
\text { and feelings that arise in a situation; and identify cognitive distortions. }\end{array}$ \\
\hline Session 3 & $\begin{array}{l}\text { Discussing the ideal body image in the media and how it affects oneself; trying to have a more } \\
\text { realistic view of the body and fighting the negative thoughts (counter for negative thoughts) by } \\
\text { doing self-affirmation (making mantras). }\end{array}$ \\
\hline Session 4 & $\begin{array}{l}\text { Getting to know themselves deeply by identifying their values and potential, appreciating each } \\
\text { other's positives, and making plans/targets for the future following their values and potential. }\end{array}$ \\
\hline Session 5 & $\begin{array}{l}\text { Understanding the concept of a healthy romantic relationship; increasing the ability to } \\
\text { communicate assertively and active listening that can be applied in future romantic relationships. }\end{array}$ \\
\hline Post-session & $\begin{array}{l}\text { Identifying changes that are owned after following a series of interventions; taking the final } \\
\text { measurement (post-test); providing an evaluation of the group intervention; and termination. }\end{array}$ \\
\hline
\end{tabular}

\subsection{Measurements}

To measure the level of self-esteem (SE), researchers used the Rosenberg Self-esteem Questionnaire (RSES). The Rosenberg Self Esteem Scale was developed by Rosenberg [22], consists of 10 items, and is a unidimensional measurement tool that measures self-esteem globally [23]. Items will be responded based on a 4 Likert scale where 0 stands for "not suitable" and 3 represents "very suitable." The higher the score, the higher the self-esteem.

To measure the body image $(\mathrm{BI})$, participants also filled out a self-rating from 1 to 10 indicating how satisfied the participant was with her body and appearance ("How satisfied are you with your body and appearance right now?"). A score of 1 indicated that the participant was very dissatisfied with her appearance, while 10 indicated that the participant was very satisfied with her appearance. The data were then processed using a paired sample T-test to compare the participants' mean scores. Furthermore, the quantitative data collected would also be supported by interviews with experimental group participants after undergoing all intervention activities.

\section{RESULT}

From the online recruitment process, 35 prospective participants were willing to take part in online group therapy. Furthermore, based on the results of interviews by phone, 14 participants matched the criteria previously mentioned. Participants were then divided into two groups: the experimental group and control group, each of which had 7 participants.

In the experimental group, participants had an average age of 22 years $(S D=2.00)$, likewise in the control group $(\mathrm{SD}=2.38)$. The majority of the participants' latest education level in both groups was senior high school (64.29\%), university (35.71\%). Similarly, in terms of work, most of the participants both in the experimental group and the control group were college students (64.29\%), employed (28.57\%), and self-employed $(7.14 \%)$. Participants came from various regions in Indonesia, but those from Java 
were dominant $(85.72 \%)$, Sumatra $(7.14 \%)$, and Sulawesi $(7.14 \%)$.

The results (see Table 2) showed that in the selfesteem variable, the experimental group had a significant difference in mean scores before and after undergoing group intervention with the online CBT approach (strong effect size). Meanwhile, there was no significant difference in mean scores between pretest and post-test in the control group. These show that group intervention using the online CBT approach can increase self-esteem in the experimental group.

Furthermore, on the body image variable measured using a self-rating from 1-10, the experimental group showed a significant difference in mean scores before and after group intervention with the online CBT approach (moderate effect size). In the control group, there was no significant difference in mean scores between pre-test and post-test. These results suggest that group intervention using the online CBT approach can increase body satisfaction in the experimental group.
Table 2. Results on Experimental Group and Control Group

\begin{tabular}{|c|c|c|c|c|c|c|c|}
\hline & \multicolumn{2}{|c|}{ Pre-test } & \multicolumn{2}{|c|}{ Post-test } & \multirow{2}{*}{$t$} & \multirow{2}{*}{$p$} & \multirow{2}{*}{$\begin{array}{c}\text { Cohen's } \\
\quad d\end{array}$} \\
\hline & $M$ & $S D$ & $M$ & $S D$ & & & \\
\hline \multicolumn{8}{|c|}{ Experimental Group } \\
\hline SE & 13.86 & 3.93 & 20.00 & 2.38 & -3.78 & 0.009 & 1.43 \\
\hline BI & 5.57 & 2.07 & 7.42 & 0.53 & -2.51 & 0.045 & 0.95 \\
\hline \multicolumn{8}{|c|}{ Control Group } \\
\hline SE & 12.00 & 3.21 & 14.57 & 3.59 & -2.36 & 0.056 & \\
\hline BI & 4.85 & 1.95 & 5.28 & 1.89 & -0.75 & 0.482 & \\
\hline
\end{tabular}

Based on the interviews with experimental group participants at the post-session, participants stated that they experienced changes after participating in the intervention activity. The following is a summary of the interviews obtained from the seven participants regarding what they got from the group intervention session (see Table 3).

Table 3. Self-evaluation of Experimental Group

\begin{tabular}{|l|l|}
\hline Topic & Examples quote \\
\hline Group support & $\begin{array}{l}\text { "I realize that the experience of having difficulty in initiating romantic relationships that I felt was } \\
\text { natural for women in my age ..." "Now, I know that other participants in the therapy group have the } \\
\text { same difficulties." "... each participant can have their problems, which, however, it can be dealt } \\
\text { together, so that I feel more relieved knowing that I am not alone." "There are many things that I } \\
\text { understand and realize when I share stories with other people and listen to other people's stories." }\end{array}$ \\
\hline $\begin{array}{l}\text { Less negative } \\
\text { feelings }\end{array}$ & $\begin{array}{l}\text { "This group therapy activity makes me more positive and more confident." "My feelings have become } \\
\text { calmer, and my thoughts have become more positive." "After studying the material in the therapy } \\
\text { session, I learned to make room for the sadness that I felt, then practiced self-affirmation so that the } \\
\text { intensity of the uncomfortable feelings could be reduced." "I am more in control of the negative } \\
\text { feelings I used to experience." }\end{array}$ \\
\hline Less insecure & $\begin{array}{l}\text { "The insecure feeling that I had been feeling so strong is also gradually diminishing; the opinions of } \\
\text { others would not affect me." "Now, when someone talks about my shortcomings in the form of taunts, I } \\
\text { will be even more indifferent ..." "I do not keep thinking about the negative talk that other people say." }\end{array}$ \\
\hline $\begin{array}{l}\text { Self- } \\
\text { awareness }\end{array}$ & $\begin{array}{l}\text { "... I get to know myself better, better understand my values." "Now I have a better understanding of } \\
\text { priority values and what things need to be worked on to achieve my goals in the future." "I am starting } \\
\text { to be able to receive compliments and realize that it is part of my potential." }\end{array}$ \\
\hline Assertiveness & $\begin{array}{l}\text { "I become more able to convey my feelings and reject things that do not fit my needs or principles." } \\
\text { "Implementing assertive communication with other people gives me clearer and more convincing } \\
\text { answers, keeping me from asking myself questions." }\end{array}$ \\
\hline
\end{tabular}




\begin{tabular}{l|l}
$\begin{array}{l}\text { Self- } \\
\text { acceptance }\end{array}$ & $\begin{array}{l}\text { "... A series of group therapy helped me to be more accepting of myself and to love myself more." "I } \\
\text { am more accepting of myself, and I am not sad because of my shortcomings." "... what is important is } \\
\text { my judgment because I am the one who knows myself the most." }\end{array}$
\end{tabular}

This study results showed that online group intervention with the CBT approach effectively increases self-esteem in women aged 18-25 who find it challenging to establish romantic relationships. These results are consistent with previous research by Fennell [24], which stated that interventions with the CBT approach effectively increase self-esteem. Furthermore, Morton, Roach, Reid \& Stewart [25] also found that therapy with the CBT approach is effective in helping women with low self-esteem.

\subsection{Discussion}

Low self-esteem can be one of the causes for individuals to hesitate to establish romantic relationships with other people. As explained by Pratiwi [26] explained that individuals with low selfesteem have difficulty forming and maintaining an intimate relationship. Individuals with low selfesteem also have characteristics in which they tend to be dissatisfied with their appearance, feel unattractive, and think that other people also tend to judge them negatively. Therefore, in this group intervention, individuals with low self-esteem were directed to recognize the negative thoughts that prevented them from establishing relationships. Individuals also need to be encouraged to develop a more realistic view of themselves and recognize their potential, so they do not just focus on their shortcomings.

This group intervention could also increase participants' satisfaction with their body/appearance. This statement is in line with what was explained by Esplen and Tratchtenberg [18], that online intervention with the CBT approach is one of the interventions that could show positive results for participants with a negative body image. Other research also stated that the CBT approach can enhance a more positive body image in women [27] [28]. Greenberg et al. [29] stated that low self-esteem is also related to how individuals assess their appearance negatively (negative body image) so that the CBT approach, which aims to increase selfesteem, can also help participants assess their appearance more positively. Individuals are also encouraged to recognize other things outside their appearance that can make them feel attractive and valuable, so they do not just focus on dissatisfaction with their appearance.

The online group intervention can also provide several benefits, including: effective and efficient in helping several participants who have similar problems at the same time even though it is done online; letting the participants feel they are not alone and receive support from other participants who have similar problems; showing that the experiences and understandings of other participants that are conveyed during the session can increase the participants' learning in dealing with problems they face, as well as broadening perspectives in seeing the problems they have; letting the participants get a comfortable and safe place to bring up the problems they are facing without getting negative judgments from others; and facilitating the participants to be more open to the environment, adding new insights, and training their ability to communicate assertively in groups. Also, online group intervention can be an option for intervention during the COVID-19 pandemic because it does not require face-to-face meetings and can be done flexibly and efficiently.

\subsection{Conclusion and limitation}

It can be concluded from this study that the online CBT approach was effective in promoting selfesteem for women between the age 18 and 25 to develop romantic relationships. The online CBT approach helped build positive outlook and confidence about themselves.

This study was faced with several limitations, including those related to online intervention activities. The unavoidable obstacle was the distraction during the session. Participants might experience interference from home conditions, such as being invited to chat by their families or doing other things outside of intervention activities. In participant observation, the facilitator was also unable to carry out comprehensive observations because they only relied on a video camera pointed at the shoulders to the head of the participants. 
Participants' activities were less observable, mostly when their internet connection was low, and they could not turn on their video camera. Further testing (follow-up) upon participants in the online intervention group is also necessary to determine the extent to which the positive impact of therapy can be sustained over time.

Further research related to online-based psychological interventions is needed, given that the use of computers, smartphones, and the internet is increasingly common. In the next few years, the use of gadgets and internet access is likely to expand, so that this research is expected to prepare other psychological interventions that will take advantage of technological advances in Indonesia. That way, psychological intervention can reach people in various areas, not only in big cities. Online group intervention relies on the availability of electricity, adequate devices, and a stable internet connection. It is still difficult to apply to all participants because the participants are scattered in various regions, and the facilities they have are different. It is in line with Fox [30], who stated that people living in remote areas and those with low income tend to have less access to high-speed internet connections than people in big cities. Future research needs to take these challenges into account and undertake more careful planning before undertaking psychological intervention online.

\section{AUTHORS' CONTRIBUTIONS}

DTP conceived the study. DTP collected the data, implemented the methods, performed the experiments, analyzed the results, and wrote the manuscript. LH supervised all the process. Both authors read and approved the final manuscript.

\section{ACKNOWLEDGMENTS}

We want to thank all the participants and the cofacilitators (Anggita Hotna Panjaitan, S.Psi., Prawestri Bayu Utari, S.Psi., and Olphi Disya Arinda, S.Psi) for their participation in this research. This research is supported and funded by the Universitas Indonesia.

\section{REFERENCES}

[1] J. Arnett. Emerging adulthood: A theory of development from the late teens through the twenties. Am Psychol., 55(5) (2000) 469-480. DOI: $10.1037 / / 0003-066 x .55 .5 .469$

[2] E. Luciano, U. Orth. Transitions in romantic relationships and development of self-esteem. J Pers Soc Psychol. 112(2) (2017) 307-328. DOI: 10.1037/pspp0000109

[3] M.K. DeGenova, Intimate Relationship Marriages \& Families. New York: McGraw Hill, 2008.

[4] J. Beckmeyer, S. Cromwell. Romantic relationship status and emerging adult wellbeing: Accounting for romantic relationship interest. Emerg. Adulthood. 7(4) (2018) 304308. DOI: $10.1177 / 2167696818772653$

[5] U. Orth, R. Robins, K. Widaman. Life-span development of self-esteem and its effects on important life outcomes. J Pers Soc Psychol. 102(6) (2012) 1271-1288. DOI: $10.1037 / \mathrm{a} 0025558$

[6] J.W. Santrock. Adolescence (15th ed.). New York: McGraw-Hill Education, 2014.

[7] R.A. Baron, N.R. Branscombe, D. Byrne. Social Psychology (13 ${ }^{\text {th }}$ Ed.). New Jesey. Pearson Education, Inc, 2011.

[8] C.J. Mruk. Self Esteem Research, Theory and Practice: Toward a Positive Psychology of Self Esteem. 3rd Ed. New York: Springer Publishing Co, 2006.

[9] S. Harter. The Construction of The Self: A Developmental Perspective. New York: Guilford Press, 1999.

[10] D. Clay, V. L. Vignoles, H. Dittmar. Body image and self-esteem among adolescent girls: Testing the influence of socio-cultural factors. J Res Adolesc. 15 (4) (2005) 451-477.

[11] G. Tiwari. Body image satisfaction enhances self-esteem. A Multidisciplinary Peer Reviewed Refereed. Int. Res. J. 4 (4) (2014) 7-11.

[12] R. Craven, H.W. Marsh. The centrality of the self-concept construct for psychological wellbeing and unlocking human potential: Implications for child and educational psychologists. Educ. Child Psychol. 25 (2008)104-118. 
[13] L. Wasylkiw, L.A. MacKinnon, M.A. MacLellan. Exploring the link between selfcompassion and body image in university women. Body Image, 9 (2012) 236-245. DOI: 10.1016/j.bodyim.2012.01.007

[14] V. Zeigler-Hill. The connections between selfesteem and psychopathology. J. Contemp. Psychother. 41(3) (2011) 157-164. DOI: $10.1007 / \mathrm{s} 10879-010-9167-8$

[15] A.E. Bos, P. Muris, S. Mulkens, H.P. Schaalma. Changing self-esteem in children and adolescents: A roadmap for future interventions. Neth. J. Psychol. 62(1) (2006) 26-33.

[16] P. Stallard. A Clinician's Guide to Think GoodFeel Good: Using CBT with Children and Young People. Chichester: Wiley, 2002.

[17] M. Fennell. Cognitive therapy in the treatment of low self-esteem. Adv Psychiatr Treat. 4(5) (1998) 296-304. DOI: 10.1192/apt.4.5.296

[18] M. Esplen, L. Trachtenberg. Online interventions to address body image distress in cancer. Curr. Opin. Support Palliat. Care. 14(1), (2020) 74-79. DOI: $10.1097 /$ spc.0000000000000484

[19] L. Warmerdam, A. Straten, J. Jongsma, J. Twisk, P. Cuijpers. Online cognitive behavioral therapy and problem-solving therapy for depressive symptoms: Exploring mechanisms of change. J Behav Ther Exp Psychiatry. 41 (2010) 64-70. DOI: 10.1016/j.jbtep.2009.10.003

[20] G. Andersson, P. Cuijpers. Pros and cons of online cognitive-behavioural therapy. $\mathrm{Br} J$ Psychiatry 193(4) (2008) 270-271. DOI: 10.1192/bjp.bp.108.054080

[21] L. Ellis, A. Campbell, S. Sethi, B. O’Dea. Comparative randomized trial of an online cognitive-behavioral therapy program and an online support group for depression and anxiety. J Cyber Ther Rehabil. 4(4) (2011) 461-467.

[22] M. Rosenberg, C. Schooler, C. Schoenbach, F. Rosenberg. Global self-esteem and specific selfesteem: different concepts, different outcomes. Am. Sociol. Rev. 60(1) (1995) 141. DOI: 10.2307/2096350
[23] D. Schmitt, J. Allik. Simultaneous administration of the Rosenberg self-esteem scale in 53 nations: Exploring the universal and culture-specific features of global self-esteem. J Pers Soc Psychol. 89(4) (2005) 623-642. DOI: 10.1037/0022-3514.89.4.623

[24] M. Fennell. Low self-esteem: A cognitive perspective. Behav Cogn Psychother. 25(01) (1997) 1. DOI: 10.1017/s1352465800015368

[25] L. Morton, L. Roach, H. Reid, S. Stewart. An evaluation of a CBT group for women with low self-esteem. Behav Cogn Psychother. 40(2) (2011) 221-225. DOI: $10.1017 / \mathrm{s} 1352465811000294$

[26] P. Pratiwi. Cognitive behavior therapy (CBT) untuk meningkatkan self-esteem pada dewasa muda yang mengalami kekerasan dalam pacaran (Postgraduate), 2016, Universitas Indonesia.

[27] S. Cassone, V. Lewis, D. Crisp. Enhancing positive body image: An evaluation of a cognitive behavioral therapy intervention and an exploration of the role of body shame. Eating Disorders, 24(5) (2016) 469-474. DOI: 10.1080/10640266.2016.1198202

[28] H. Lewis-Smith, P. Diedrichs, E. Halliwell. Cognitive-behavioral roots of body image therapy and prevention. Body Image, 31 (2019) 309-320. DOI: 10.1016/j.bodyim.2019.08.009

[29] J. Greenberg, S. Markowitz, M. Petronko, C. Taylor, S. Wilhelm, G. Wilson. Cognitivebehavioral therapy for adolescent body dysmorphic disorder. Cogn Behav Pract. 17(3), 2010, pp. 248-258. DOI: 10.1016/j.cbpra.2010.02.002

[30] S. Fox. Americans living with disability and their technology profile, 2011, Available from: http://www.pewinternet.org/ /media//Files/Repo rts/2011/PIP_Disability.pdf. 